\title{
Purificando la tierra, colonizando el espíritu: conflicto armado y religiosidad en la mítica Marquetalia*
}

\author{
A la gracia de Rogelio Paredes.
}

\section{Resumen}

El quebrado territorio de la cordillera central en Colombia ha sido el epicentro de luchas políticas, militares y especialmente espirituales en las que el territorio en pugna, la mítica zona de Marquetalia, debate creencias y prácticas, en torno al poder, la sangre y la tierra. Lógicas de diverso orden que vinculan la lucha armada, la conquista espiritual y la cosmología del pueblo indígena Nasa -que habita en la zona-, ponen acento crítico en una tensa relación que confronta a la vez que vincula el orden político con el actuar religioso. Este trabajo, centrado en las relaciones emergentes de un campo etnográfico, busca dar cuenta de acciones y relaciones que articulan y condensan tales enfrentamientos, al mismo tiempo que sugiere un marco de interpretación desde las prácticas religiosas que evidencia la forma en que varios elementos del conflicto armado en Colombia tienen como móvil un componente espiritual.

Palabras Clave: Colombia, Marquetalia, Pueblo Nasa, territorio, violencia, religión.

Referencia para citar este artículo: OSPINA, Andrés Felipe (2015). "Purificando la tierra, colonizando el espíritu: conflicto armado y religiosidad en la mítica Marquetalia”. En Anuario de Historia Regional y de las Fronteras. 20 (2). pp. 101-124.

Andrés Felipe Ospina: Candidato a doctor en Antropología de la Universidad de Los Andes, Bogotá. Antropólogo de la Universidad Nacional de Colombia, sede Bogotá. Becario Colciencias, programas de doctorados Nacionales. Correo electrónico: andesosama@gmail.com.

\footnotetext{
"Esta investigación se desarrolló en el marco del proyecto de investigación doctoral "Sembrando muertos, cosechando espíritus: relaciones de vida y muerte, violencia y orden territorial en los Nasa del sur del Tolima”, en el doctorado en Antropología de la universidad de los Andes (Colombia). La información y las reflexiones presentes en este artículo corresponden al trabajo de campo etnográfico desarrollado con la comunidad indígena Nasa Wesx de Gaitania (Tolima) a lo largo del 2012 y 2013.
} 


\title{
Purifying the earth, colonizing the spirit: armed struggle and religiousness in the mythical Marquetalia
}

\begin{abstract}
The hilly land of the central mountain range in Colombia has been the epicenter of political, military and especially spiritual fights in which the land being vied, namely, the mythical zone of Marquetalia, discusses beliefs and practices around power, blood and land. Different kinds of thinking that bind together the armed struggle, the spiritual conquest and the cosmology of the Nasa indigenous tribe - which lives in that zone -, seriously accentuate a tense relationship that simultaneously creates a clash and a bond, between political order and religious deeds. This paper, focused on the emerging relations of an ethnographic field, intends to account for the actions and relationships that configure and condense said clashes, and in turn suggests an interpretation framework from religious practices that accounts for the way how several elements of the armed struggle in Colombia have a spiritual motivation.
\end{abstract}

Keywords: Colombia, Marquetalia, Nasa people, territory, violence, religión.

\section{Purificando a terra, colonizando o espírito: conflito armado e religiosidade na mítica Marquetalia}

\begin{abstract}
Resumo
O quebrado território da cordilheira central na Colômbia foi o epicentro de lutas políticas, militares e especialmente espirituais nas que o território em pugna, nomeadamente a mítica zona de Marquetalia, debate crenças e práticas em torno ao poder, o sangue e a terra. Lógicas de diversa ordem que vinculam a luta armada, a conquista espiritual e a cosmologia do povo indígena Nasa - que habita na zona - , acentuam criticamente uma tensa relação que confronta ao mesmo tempo que vincula a ordem política com o agir religioso. Este trabalho, centrado nas relações emergentes de um campo etnográfico, busca dar conta de ações e relações que articulam e condensam tais enfrentamentos, assim como surge um marco de interpretação desde as práticas religiosas que na conta da forma em que vários elementos do conflito armado na Colômbia têm como móbil uma base espiritual.
\end{abstract}

Palavras-chave: Colômbia, Marquetalia, as pessoas da Nasa, território, violência, religião. 


\section{Introducción}

Marquetalia es una cumbre y una mira. Los hombres que han intentado ascender a su cima, en los distintos momentos de la guerra, se han enfrentado a una vigilancia extrema que responde con fuego a cada movimiento. El cerro ha estado tomado por grupos armados que en los momentos más críticos de la guerra política en Colombia lo han hecho un fortín, un santuario. Defenderlo implica cortar el paso a todo contrario, evitar el acceso de quienes no comparten las armas, la fe o lo doctrina con el bando que tiene el control. En los bordes de su quebrada geografía, los hombres han sembrado, entre combates y alzamientos sucesivos, dos elementos propios de toda lucha: sangre y espíritu. El enfrentamiento de los hombres hace germinar de dichas sustancias una serie de formas sagradas que marcan el camino de la reyerta, con rumbo hacia dos materias vivas, contaminantes, apasionadas, totales, delirantes, efímeras: territorio y poder.

En el tope de ese Marquetalia, un pequeño cerro que permite una vista extendida de las tierras altas y bajas de la cordillera central, cuenta doña Edilma Paya que se asentó, en los años cincuenta, un comando de campesinos comunistas, provenientes del Cauca. Recorriendo los filos del cañón del río Atá, cauce central de la zona, este grupo, de unos cuantos guerrilleros rebelados contra el régimen, exponía a campesinos e indígenas los problemas de la desigualdad social, la explotación económica, la intervención extranjera en los asuntos nacionales y la lucha armada como alternativa de liberación. En el territorio ancestral Nasa Wesx, vecino a Marquetalia -al otro lado del cañón del río Atá-, el pueblo indígena Nasa conoció de este grupo. De los comunistas recibieron instrucción y en ocasiones mandato. Don Milciades Garzón, habitante de la Vereda Altamira, recuerda que los guerrilleros reunían a la gente para enseñarles de la historia de la humanidad ${ }^{1}$ o sobre el poder de las masas y los movimientos armados. Recuerda también doña Edilma que estos guerrilleros hacían cultivar a los indígenas maíz y frijol para sostener a los guerreros; a los niños se les enseñaba a marchar, a hacer paradas militares, a recibir entrenamiento y a desfilar con un palito que remplazaba a un fusil.

Sin hacer parte activa de la guerra, las comunidades de esta zona aprendieron a convivir con la gente armada. En aquellos territorios donde no se conocía al Estado -aparte de ocasionales incursiones violentas de la fuerza pública-, indígenas y campesinos tenían como referente de organización la propuesta de los grupos armados de una u otra laya, quienes con el arma y la doctrina orquestaban las posibles formas de poder. Rememora Edilma que, cuando era muy niña, una vez apareció sobre el cielo del cerro Ucrania, sitio del primer comando comunista en la zona, (frente a Marquetalia), un avión grandísimo que tenía forma de marrano, de este llovieron

\footnotetext{
${ }^{1}$ En una conversación informal, don Milciades contó que los guerrilleros enseñaban: que primero los hombres vivían como primitivos y que después ya eran capitalistas. Que entre esos dos momentos hubo otro periodo que llamaban el "guaudal", pero que no recordaba cómo era. El "guaudal" es un nido de matas de "guauda" -así es como en la zona llaman a la guadua-. Con el tiempo y las palabras, caí en cuenta que la conversación de don Milciades era una entrada al materialismo histórico aprendido en la profunda cordillera, en donde un "guaudal" podía equipararse con el periodo "feudal".
} 
Purificando la tierra, colonizando el espiritu: conflicto armado y religiosidad...

papelitos. Se acuerda que su mamá miró uno de esos papelitos y comenzó a llorar, otros se abrazaron y poco después algunos estaban ansiosos, nerviosos, con ganas de hacer trasteo y salir. Esa fue la vez que el gobierno militar del general Rojas Pinilla en 1953 ordenó una amnistía para aquellos grupos guerrilleros que se habían alzado contra el gobierno. En el ambiente de dicha amnistía, los guerreros - de corte liberal algunos, conservadores otros, comunistas los menos, campesinos e indígenas todosse encontraban, en su mayoría, agotados de una lucha armada que les obligó a dejar su tierra, trabajo y núcleo social. Los comandos guerrilleros dieron vía libre a sus militantes para que aceptaran o rechazaran la amnistía. Sin embargo, advirtieron que los propósitos del Estado no eran la paz ni la reconciliación, con el tiempo vendría una represión mayor a la que en esa época se vivía y la única garantía para mantenerse con vida y organizados era la lucha armada. Jaime Guaracas, un guerrillero histórico de las Fuerzas Armadas Revolucionarias de Colombia (FARC), cuenta cómo la gran mayoría de combatientes, deciden salir de la selva. Unos pocos se quedan, retando al gobierno militar y su presunta apertura ${ }^{2}$. Con los años, el conflicto recrudeció y los aviones en forma de marrano ahora hacían llover fuego. De aquel movimiento guerrillero que combatió varias veces contra el Ejército Nacional, se desarrollaría más adelante lo que hoy se conoce como la guerrilla de las FARC.

En persecución de estos grupos armados, el Ejército Nacional lanzó en mayo de 1964 un fortísimo ataque sobre la zona. Con su punta de lanza de la época, el Batallón Colombia desplegó un ataque por aire y tierra, en contra de los grupos de campesinos armados. Sustentando en un ambiguo discurso de razón y fuerza, el propósito era recuperar estos territorios y sus pobladores para el Estado, debido a que era inadmisible que otro orden diferente al propio se diera en las zonas que por mandato legal debería controlar. Del otro lado, los grupos de campesinos comunistas exigían que la presencia del gobierno se representara en inversión social, en apoyo para esas poblaciones aisladas. Pero estos llamados solo fueron contestados con las maniobras desplegadas en aquella selva que poco a poco tomó el tinte de teatro de operaciones militares.

Entre una y otra fuerza, cada cuerpo de combatientes ha convertido, o a lo menos interpretado, la dinámica temporal y espacial de Marquetalia en un círculo de prácticas y relaciones que superponen una cosmología ancestral, sostenida en el pensamiento de indígenas y campesinos del sur del Tolima, así como en las formas simbólicas, predadoras, políticas y viscerales de una guerra por posesión de territorio. Cada quien desenvuelve una línea y un argumento de formas y prácticas en su hacer social ${ }^{3}$, que traen consigo un ordenamiento ideológico y espacial del territorio. Para los propósitos de este artículo entraremos a observar cómo los atributos de un espacio y su naturaleza, representada en esquemas culturales, se traslapan con las reacciones que produce un conflicto armado en el interior de una sociedad habituada al peso de la guerra.

\footnotetext{
${ }^{2}$ ARANGO, Carlos, FARC veinte años. De Marquetalia a la Uribe, Bogotá, Ediciones Aurora, 1984, p. 116.

${ }^{3}$ INGOLD, Tim, Lines a Brief History, New York, Routledge, 2007, p. 8.
} 
En la cosmología Nasa el agua y la tierra contienen espíritus de dos clases: $k s x a{ }^{\prime} w$, que son los espíritus de la noche, e I'kwesh'sx, los espíritus del día. Ambos habitan en los caminos del agua, los fondos de la cordillera central, las lagunas, las elevaciones sagradas, los límites del territorio y aquellos espacios naturales que todavía no han sido "domesticados" por el Nasa; es decir, son espacios que no pertenecen a la gente, pero que hacen parte de una traza universal, cósmica, que da sentido a la vida social, a la creencia, al ordenamiento. Los espacios han cobrado forma con la fuerza y el movimiento del pensamiento, así mismo con los embates de esas luchas políticas y militares que se han sucedido en el tiempo de los indígenas y otras gentes. Los primeros hombres que transitaron la zona de la actual Marquetalia llegaron huyendo de la Guerra de los Mil Días y de la pobreza producto de la violencia en el Cauca ${ }^{4}$, a comienzos del siglo XX. Al encontrarse un territorio boscoso y sin camino, los Nasa descumbraron ${ }^{5}$ la selva, fundaron los lugares con topónimos que recuerdan los sitios de origen o las formas naturales que iban descubriendo. En la tumba de monte, en la entrada a las montañas comenzaron a sentirse los mohanos, los duendes, el Arco y el Trueno, todos personajes fantásticos de la cosmología Nasa; junto a los espíritus, fueron seres que también llegaron con el hombre y su pensamiento, dando forma y tenencia a estos nuevos territorios transitados.

Las entradas del combate también calan las formas de los espacios. En las verticales geografías de Marquetalia, los movimientos de la tierra y el agua corresponden con los movimientos del asalto, con la tensión de un ataque. Las quebradas y ríos han formado profundos cañones, caminos del agua sobre los cuales también circula la gente, pues aquí los caminos de los hombres se dibujan y traslapan siguiendo los caprichos geológicos; por eso los hombres aprenden a caminar de manera tan sinuosa, a marchar la tierra. Aquellos cañones son la seña donde se ponen las huellas de antiguas y recientes migraciones, de antiguos y recientes bombardeos. Un asalto es una incursión veloz, su duración es efímera pero sus marcas son constantes. Las huellas de la lucha armada se forjan a la manera de un volcán ${ }^{6}$ o de una avalancha que se desprende, como el paso ligero del agua en un torrente desbocado. Esos violentos movimientos quedan signados, quizá consagrados de forma permanente, como lo hace el flujo incesante del agua por entre los cauces que ha ido tallando el cañón en furiosos temporales. Dicho de otra manera, las fluctuaciones de la guerra se dan en una simpatía constante con las formas y los tiempos de los fenómenos naturales. Emboscarse en el monte para agarrar por sorpresa al enemigo desde lo alto, es tan parecido a la creciente de un río que desde la cima desbordada lanza sus aguas cargadas y arrasa con las desprevenidas tierras de abajo. A la par, el correr incesante de las aguas es un símil de

\footnotetext{
${ }^{4}$ Región originaria del pueblo Nasa.

${ }^{5}$ Descumbrar es tumbar las partes más espesas y elevadas de un monte para allí establecer cultivos. Se hace en dos momentos, primero se tumba la vegetación más pequeña y mientras esta se seca, se tumba la vegetación más grande, luego se prende fuego y el resto seco del primer corte aviva el fuego que calcina todo. Otro nombre que recibe es el de socolar.

${ }^{6}$ Para la semántica de las altas cordilleras "volcán” es un violento movimiento de tierra que genera un desprendimiento de la montaña, formando vuelcos o volcanes que taponan caminos y cursos de agua. De los mismos pueden formarse "valanchas", movimientos más bruscos aun de agua y tierra que pueden "revolcar" los extensos corredores rivereños y cargarse con todo lo que encuentren a su paso.
} 
Purificando la tierra, colonizando el espiritu: conflicto armado y religiosidad...

la sangre torrentosa dentro y fuera de los cuerpos, animando al combate, luchando la tierra, resignando la muerte.

Esos silogismos entre agua, sangre, movimiento, tierra y lucha, que reflejan la eterna disyuntiva entre naturaleza y cultura, son útiles para ahondar en las relaciones emic, base y alternativa de posibles sistemas de relación en torno a las manifestaciones de la violencia, de lo terrígeno y de lo sagrado, materias vinculantes de un territorio en disputa. Aquella afirmación se hace tomando como base las narrativas de indígenas y campesinos que en relatos estructurados o en sencillos comentarios describen cómo los guerreros deben conocer y hacerse a la naturaleza de esos torrentes desbocados, o de esos violentos movimientos, para hacer efectiva su lucha en dichos espacios. Tal naturaleza se extiende a la fuerza y los atributos de los mismos combatientes, que encarnan en su condición y carácter los rasgos de una naturaleza contrariada y, como los guerreros, violenta. Dice doña Crucita Paya, indígena Nasa de la vereda San Pedro, que "[...] los blancos llevan la guerra en la sangre y no pueden vivir sin pelear"' La llevan tan en la sangre, que esta influye y señala en qué bando y de qué modo luchar. Dicen además en la región que la sangre tira y de acuerdo a su tono, a su ascendencia y pureza ordena los vínculos con la tierra y los demás hombres que son o no de la misma línea, de la misma sangre.

A finales de los años cuarenta, cuando las guerrillas de distintas facciones buscaron refugio en la cordillera Central, alrededor de Marquetalia, se diferenciaron dos grupos de rebeldes. Por un lado, los Liberales o "Limpios" que seguían la línea política del Directorio del Partido Liberal, el cual buscaba retomar el control del gobierno nacional. Por otro, los comunistas, también llamados "Comunes", quienes pretendían el poder por medio de una lucha revolucionaria que cambiara las estructuras económicas y políticas. Los Limpios acusaban a los Comunes de ateos, de seguir la doctrina socialista de Rusia, de no respetar a la familia, ni a la virgen María, ni a la propiedad individual. Los “Comunes" eran entonces sucios, antítesis de los "Limpios". Durante algún tiempo, cuando la presión militar del Estado era insostenible, ambos bandos lucharon de manera conjunta, sin embargo, las diferencias jamás cesaron; entre las dos facciones se dieron refriegas intestinas que debilitaron el movimiento guerrillero, causando muchas muertes de un lado y de otro.

Pese a todo, en las tierras del sur de Tolima, zona donde se enclava Marquetalia, ambas sangres abatidas se mezclaron. Indistinto del bando, cuando la sangre va a la tierra se entrecruzan las líneas de afinidad. Si bien el origen de cada partida puede ser distinto, para todos la idea de destino, de un destino final, un llamado a la muerte, es una razón común. Dice don Víctor Urueña que "la muerte no tiene miramientos. La muerte se lleva al grande o al chico, al rico o al pobre, al joven o al viejo, al negro o al blanco, a toditos por igual". A la tierra, "esa coloca ${ }^{8}$ en el cementerio", llegamos todos, la vida termina siendo aquel camino -más largo o más corto- en el que empezamos a

${ }^{7}$ FLÓREZ, Diego, Buscando a Gaitania. La crónica de una región que cambió para siempre la historia de Colombia, Ibagué, Caza de Libro Editores, 2011, p. 53.

${ }^{8}$ Como llaman en los campos del Tolima al lugar de habitación. 
morir desde que nacemos. Cuando el momento final llega, quien se queda con todo es la tierra. En una región atravesada por la guerra como es el departamento del Tolima, todos los caídos siguen nutriendo los campos, siguen haciendo la rúbrica. La bandera del departamento tiene dos franjas, una en color oro, que exalta la riqueza de su tierra, otra en color vinotinto, que encarna la sangre que sobre ella se ha derramado... y se derrama. Pero antes de caer en tierra, la sangre cae sobre las armas, por lo que los "fierros" pueden tenerse como un mecanismo de vínculo parental": "ser hermanos en las armas"; los lazos de afinidad se construyen en torno a la guerra, en donde la sangre que une es la que está dispuesta a ser derramada (entregada en la lucha) y no tanto la que busca ser contenida, como ocurre con los vínculos sanguíneos de parentela. En esa relación, los señores de la guerra, hombres notables de un carisma y una fuerza incontenible (una suerte de padres de la sangre derramada), han estado y están dispuestos a sacrificar, a seguir sembrando sangre para cosechar, conquistar o defender tierra. Aquella, es la raigambre de Marquetalia.

\section{Vivos y muertos, militares y guerrilleros a la toma de Marquetalia}

A la intervención militar de 1964 se le dio el nombre de "Operación Marquetalia". En esta el Ejército Nacional (como entonces declararían sus mandos) no solo intentó controlar el estratégico espacio donde se resguardaban los grupos de campesinos comunistas, también buscó hacerse a la extensa zona del sur del departamento del Tolima; una región de $5.000 \mathrm{Km} 2$ donde movilizó a varios miles de efectivos, filtró los caminos de acceso, instaló bases aéreas y lanzó a la población civil todo un proyecto de "rehabilitación", cuyo propósito era que "El gobierno recuperara el control de la zona y repusiera allí el imperio de la ley"10, de tal manera "desarticular el imperio del terror" 11 . Para el Estado, aquellos grupos forjaron en estas zonas de difícil acceso lo que el congresista Álvaro Gómez Hurtado llamó "Repúblicas Independientes", zonas domeñadas por rebeldes y no por el Estado, situación que desde el Parlamento se exigió revertir.

La "Rehabilitación" era entendida como un proceso que garantizaba, mediante la presencia de los agentes del Estado, el ejercicio de la legítima autoridad. Para ello se orquestó una acción cívico-militar que traía, a juicio de los estadistas y militares, garantías para los campesinos azotados por el "bandolerismo", que ahora podrían vivir en paz con un Ejército que los protegía y les colaboraba para superar sus penosas condiciones de vida. Según el Coronel Currea Cubides, comandante de esta operación, “[...] el Ejército está dispuesto a llegar al corazón del campesino para devolverle la paz y tranquilidad que Colombia quiere para todos"12. El mismo militar, en una entrevista concedida al diario El espectador decía que el propósito central era "Reincorporar esa

\footnotetext{
${ }^{9}$ PÁRAMO, Carlos, "El corrido del minero: hombres y guacas en el occidente de Boyacá", en Maguaré, No. 25, Bogotá, Universidad Nacional de Colombia, 2011, p. 68.

10 "El país puede estar tranquilo y seguro de sus fuerzas armadas", en El espectador, 6 de Mayo, 1964. p. 6.

${ }^{11}$ Ibid., p. 6.

${ }^{12}$ El espectador, 27 de Mayo de 1964, p. 27.
} 
Purificando la tierra, colonizando el espiritu: conflicto armado y religiosidad...

región a la patria" ${ }^{13}$. En medio del tono bélico, un orgullo de los mandos militares era demostrar el carácter pacifista de esta operación, ya que un despliegue de este calibre se había efectuado durante sus primeros días sin la necesidad de hacer un solo disparo. Eso sí, el mismo Currea Cubides advirtió que "[...] eran los bandoleros quienes con las armas rechazaban la rehabilitación e incorporación a la vida jurídica de dichos territorios"14, razón por la cual, de ser necesario, el peso de la fuerza militar sería dirigido contra los grupos de bandoleros, pero jamás contra el "pacífico campesino".

Para el Estado, el "bandolero" era la razón de todos los males, de su extirpación dependía el futuro de estas regiones golpeadas por la violencia. En esta época, la labor de "limpieza" había dado frutos a favor del Ejército, en zonas de duro combate de la guerra bipartidista. Los batallones que operaron en la región norte del Tolima dieron de baja a bandoleros tristemente célebres que habían cobrado aciagas recordaciones en la cadena de enfrentamientos a muerte entre grupos armados, liberales y conservadores ${ }^{15}$. De aquellos "bandoleros" que eran objetivo del ejército, quedaba quizá el último por reducir en la zona sur, Manuel Marulanda Vélez, también llamado "Tirofijo", y su grupo armado procomunista, considerados por los militares como el reducto final del bandolerismo, que al destruirse pondría un sello definitivo a la violencia y el terror en estos territorios. En otro apartado, el comandante Currea indicó a propósito de "Tirofijo":

Últimamente este bandido se hace pasar como comunista, a juzgar por las frases escritas en papeles que aparecen sobre los cadáveres de los soldados. Según estas frases los asaltos y ataques a las autoridades legítimas, a la fuerza pública, son reacción contra la acción comunal, la Alianza para el progreso, etc., "Tiro Fijo" engaña al pueblo y notifica a las Fuerzas Armadas en el sentido de que las tropas deben abandonar "su territorio"16.

En otro reportaje del diario El tiempo sobre la situación de Marquetalia, un campesino de la zona manifestó que los guerrilleros le indicaron: "[...] cuidado con decirle a los 'chulos ${ }^{17}$ o con prestarles ayuda porque de lo contrario, vamos a heredar su finquita, ¿no le daría lástima?”18. Contrario a los presuntos propósitos de Marulanda y su gente, el Ejército Nacional declaró que era su intención "garantizar la posesión de las tierras y designar comisiones tituladoras"19, ello con la intención de legalizar la tenencia de los predios en manos de los campesinos.

\footnotetext{
${ }^{13}$ El espectador, 28 de Mayo de 1964, p. 3 A.

${ }^{14}$ Ibid., p. 3A.

15 SÁNCHEZ, Gonzalo y MEERTENS, Donny, Bandoleros, gamonales o campesinos: el caso de la violencia en Colombia, Bogotá, Punto de Lectura, 2006.

${ }^{16}$ El tiempo, 10 de mayo de 1964, p. 6.

${ }^{17}$ Nombre que le dan los guerrilleros a los miembros de las Fuerzas Militares. Este término también es usual en las poblaciones campesinas del centro de Colombia, pues se les sigue llamando "chulos" a los militares cada vez que estos cometen algún abuso o imprudencia en contra de la población civil. El nombre deriva de la similitud que hay entre el uniforme camuflado oscuro de los militares y las plumas del chulo, gualo o gallinazo. Además dice la gente en la zona que cuando entra el Ejército se alborota la muerte, plato predilecto de los chulos, las fatales aves carroñeras.

${ }^{18}$ El tiempo, 16 de Mayo de 1964, p. 2 A.

${ }^{19}$ Ibid., p. 2 A.
} 
Más allá de todo intento propagandístico de un ejército que procuró legitimar el uso "legal" de la violencia y de encontrar en estas menciones una plena justificación a la ocupación militar, lo que puede también inferirse en la narrativa oficial es que el rebelde, llamado hasta la saciedad "bandolero", es un mal que debe ser erradicado, ya no solo por las acciones de un Ejército Pacificador ${ }^{20}$, sino también por una sociedad pacificada, que desde su celo legal y moral debe contener toda amenaza que de la misma sociedad resulte. Fiel representación de este propósito es la doctrina de "autodefensa" propuesta por José Joaquín Matallana, comandante de la última avanzada sobre Marquetalia y exitoso militar que en combate dio de baja a los "bandoleros" más renombrados del norte del Tolima. Este comandante manifestó que era necesario prevenir a la sociedad de futuros bandoleros, para ello consideraba ineludible un trabajo de "identificación y defensa" que resultara de los mismos campesinos. En una nota que comenta las acciones del Batallón Colombia luego de dar de baja a "Tarzán", el último "bandolero" abatido del Norte del Tolima, se dice sobre el futuro de la pacificación:

Uno de los proyectos del comandante [Matallana] está dirigido a capacitar a los campesinos para que puedan defenderse cuando son atacados por bandoleros, ya sean principiantes, o expertos en el asesinato.[Conversando con un campesino de la zona, Matallana] Le dijo, por ejemplo, que los campesinos muchas veces permiten la fuga de un bandolero por temor a ser sumariados. Le señaló entonces, que, aunque se le implante un sumario, nadie puede ser encarcelado por el hecho de haber dado muerte a un hombre desconocido que transitaba por las cercanías de una hacienda sin misión definida. Matallana describió a esos desconocidos como "bandoleros en potencia" y expresó que hay que eliminarlos ${ }^{21}$.

Esta voz, que puede ser entendida como el llamado a la defensa de la propiedad individual, también contiene la orden de hacer la cacería de un "oculto desconocido", de un "otro aparente"; esto es: la persecución y eliminación preventiva del potencial enemigo, la manifiesta diferencia. El mensaje fue recibido por algunos sectores de la sociedad colombiana con total beneplácito, pues justificaba el uso de la violencia contra aquellas formas ocultas de la sociedad nacional a quien la misma no quería reconocer sino mediante la rúbrica de bandolero, delincuente o enmontado. La autoridad de la fuerza se delegó entonces sobre quienes podrían extirpar tales anomias; así tomó forma y rumbo una operación militar de este calibre, que además de montar una estrategia de guerra, administró una suerte de justicia de los justos aplicada a los injustos -aquí tratados literalmente-, pues los del monte, aquellos que después se llamarían a sí mismos "Marquetalianos", no se encontraban ajustados ni jurídica, ni ideológicamente a los lineamientos de la sociedad que se fue lance en ristre contra ellos.

Otras voces en desacuerdo criticaron al ejecutivo por lanzar una persecución desmedida en contra de territorios y poblaciones que el mismo Estado otrora había dejado a su suerte. Gerardo Molina, intelectual de avanzada y para la época rector de la Universidad Libre de Bogotá, denunció que esta operación, a la que llamó "cacería",

\footnotetext{
${ }^{20}$ Como intentaron presentarse las fuerzas militares de Colombia a la opinión nacional.

${ }^{21}$ El tiempo, 31 de Mayo de 1964, p. 24.
} 
Purificando la tierra, colonizando el espiritu: conflicto armado y religiosidad...

"ha sido más de fieras que de hombres"22. Del otro lado de la línea historiográfica, el movimiento guerrillero pone una marca de quiebre y fundamenta el relato en un tenor distinto al de la autoridad de gobierno; así es referido desde la perspectiva de Jaime Guaracas, líder histórico de la guerrilla de las FARC:

[...] vino la agresión denominada Operación Marquetalia con un operativo de dieciséis mil soldados del Ejército para un área donde los dieciséis mil hombres no cabían ni parados, porque Marquetalia es un pequeño vallecito y la operación, o mejor dicho la agresión era para todas las áreas adyacentes a Marquetalia. Entonces comenzó la pelea de dieciséis mil soldados contra cuarenta y dos campesinos que no eran guerrilleros sino labriegos que querían vivir en paz con sus mujeres y sus hijos. Pero ante la agresión tuvieron que levantarse para defenderse y entonces se convirtieron, ahí sí, en guerrilla móvil al mando de Manuel Marulanda Vélez ${ }^{23}$.

Los textos donde el movimiento guerrillero hace relación de los eventos de Marquetalia $^{24}$, al igual que los trabajos históricos que resaltan dicha confrontación ${ }^{25}$, ponen énfasis en el hecho de que el golpe dado a Marquetalia fue esencial en la experiencia de la lucha armada revolucionaria; porque enseñó a los guerrilleros a desplegar sus fuerzas y empezar a desplazarse de manera permanente, siguiendo una estrategia de avances tácticos y progresivos. A nivel político, dicha estrategia los ponía en la corriente de una lucha por el poder que finalizaría con un último y gran movimiento estratégico, la toma de la capital, Bogotá. Todos los demás movimientos habrían de procurar la marcha hacia ese último propósito. Los avatares de la guerra podrían justificar tácticamente los demás hechos, por ejemplo, que Marquetalia fuera desmantelada, dejada al ejército, para de nuevo ser recuperada en otro tiempo más favorable. Es como si la presa de caza se hiciera por sí misma cazadora y aprendiera, en una suerte de juego ritual de iniciación y revelación, que al cambiar su modelo, su destino, también lo haría su fuerza, su carácter, su espíritu ${ }^{26}$. Nadie discute la expansión que tuvo el movimiento guerrillero luego de que estos combatientes huyeran del cerco a Marquetalia. El despliegue táctico trajo consigo la incorporación de nuevos combatientes que fortalecieron los grupos armados, sin embargo, quienes más aportaron al crecimiento de ese movimiento guerrillero, al menos en esta etapa, fueron los muertos. Aquellos que dejaron su sangre en tierra por el movimiento guerrillero, por las causas ideológicas, tomaron formas descomunales, difusamente míticas, que desbordaron y exaltaron los propósitos del combatiente. Un canto de propaganda de las FARC, en estilo vallenato, titulado No han muerto ${ }^{27}$ refiere tales dimensiones:

\footnotetext{
${ }^{22}$ El tiempo, 11 de Mayo de 1964, p. 1.

${ }^{23}$ ARANGO, Carlos, Op. cit., p. 30-31.

${ }^{24}$ ARENAS, Jacobo, Diario de la resistencia de Marquetalia, Medellín, Ediciones Abejón Mono, 1973; MARULANDA, Manuel, 1974, Diarios de Campaña. Medellín: Ediciones Abejón Mono.

${ }^{25}$ ALAPE, Arturo, Tirofijo: Los sueños y las montañas 1964-1984, Bogotá, Editorial Planeta, 2007; MOLANO, Alfredo, Trochas y fusiles, Bogotá, IEPRI \& El Áncora Editores, 1999.

${ }^{26}$ CANETTI, Elias, Masa y poder, Barcelona, Círculo de Lectores, 2005, pp. 173-217.

${ }^{27} \mathrm{Sin}$ autoría, sin fecha.
} 
No han muerto, están en medio de la pólvora, de pie, como mechas ardiendo.

[...] Están de pié en el río, altos como el profundo medio día, dominando las grandes llanuras, su voz encampanada de voz negra que cubren dignidad, replican la victoria.

Como el polvo caído, hermano corazones quebrantados tened fe en vuestros muertos no solo son raíces teñidas de sangre, no solo son sus pobres huesos derribados.

Madres entre angustia y muerte miradle el corazón al pobre día que nace, nuestros muertos sonríen desde la tierra levantando sus puños sobre el trigo, puños que muy firmes contradicen la muerte.

Estas líneas escritas, puestas en los homenajes clandestinos que organizan las FARC para recordar a sus líderes caídos, denotan que el aire conmemorativo de la muerte hace del sacrificio un acto heroico y del derramamiento de la sangre un motivo estético que hace del muerto un agente más activo que cualquier combatiente en vida; pues el caído conoce el dolor, el desmembramiento, pero además, en su propia extinción, este hace posible la convicción firme del combate, la fe en la victoria y una trascendencia que lo hace invulnerable, inmenso, poéticamente eterno. Estas son virtudes del guerrero que en la metáfora idealizada alimentan las razones, las causas y las prácticas de quienes siguen en el combate.

Las apologías de la suerte fatal no son exclusivas de estos grupos, son quizá una exaltación universal que se hace de la vida cuando tantas veces pende de ella la razón última y trágica. No obstante, en un conflicto armado tan prolongado como el colombiano, el capítulo de la muerte se reedita de forma permanente. El comandante "Tirofijo" murió diecisiete veces, según las cuentas que llevaba la misma guerrilla. En un reportaje de los años ochenta él mismo justificó por qué no envejecía: “Es que como me han matado tantas veces, a lo mejor he vuelto a resucitar" 28 . Los muertos de las incursiones se cuentan, según la versión, de a pocos o de a miles. Cada bando maneja proporciones distintas de los fatales resultados. Cada cual, siguiendo su manera, tiene una contabilidad de lo ganado y lo perdido; lógica de por sí maniquea que a su vez determina una historia de ganancias y pérdidas donde el otro, el enemigo, es presa de las convicciones propias. El otro con su muerte también insufla al grupo enemigo. No lo hace desde su gracia, misticismo o buen recuerdo, esas materias no las reconoce el contrario. Contaba “Tirofijo" en medio del asedio a Marquetalia: "'Pues aquí estamos. Y no es malo que vengan bastantes porque entre más vengan, más blanco dan" "29.

\footnotetext{
${ }^{28}$ ARANGO, Carlos, Op. cit., p. 90 .

${ }^{29}$ Ibid., p.31.
} 
Purificando la tierra, colonizando el espiritu: conflicto armado y religiosidad...

En medio de las bajas, a finales de junio de 1964, Marquetalia cayó en manos del Ejército Nacional. Los diarios de la época registraron, entre los primeros actos de la victoriosa toma de Marquetalia, la izada de la bandera de Colombia en el territorio "recuperado", además de una misa oficiada por el sacerdote castrense, a la que asistieron los principales mandos militares, tres ministros de Estado e invitados del alto gobierno, para pedir por la paz de la región recién "recuperada". La puesta de la bandera tiene otro motivo para el grupo de guerrilleros. Cuenta Guaracas sobre los últimos eventos de la toma:

[...] un soldado trató de ubicar una bandera para delimitar las áreas entre ellos y nosotros. Era una bandera de Colombia. Le pegamos un tiro y el soldado cayó sobre la bandera. Luego salió otro a tratar de izar la bandera y también lo tumbamos. Esta operación se repitió tres veces y ya el cuarto soldado pudo izarla arrastrándose de barriga. [...] Empezaron a ametrallarnos. Duraron como dos horas ametrallándonos. Cuando los de tierra pensaron que ya la aviación nos había hecho retirar, trataban de seguir avanzando pero nuestro fuego los hacía retroceder. Así los tuvimos hasta las seis de la tarde que el compañero Marulanda dio la orden de retirada. Nos fuimos a donde ya estaba lista la otra emboscada ${ }^{30}$.

La continuación de la guerra hizo que luego tales actos cobraran una poderosa remembranza, que puede instalar el hecho más allá de sus propios límites espaciales e históricos ${ }^{31}$. La toma de Marquetalia, para la guerrilla de las FARC nunca fue una derrota, fue más bien el despliegue de un movimiento guerrillero que dice no cesar en su objetivo de poder. En Bogotá, sobre muros de barrios populares, en las verjas del comercio de la Carrera Séptima (en el centro) y en los atiborrados frentes de entrada a las universidades públicas se leen grafitis que rezan: "Desde Marquetalia hasta la victoria, Vencer o morir, y venceremos". Estas líneas se las endosan a simpatizantes o a estructuras urbanas de la guerrilla de las FARC, que han hecho de la imagen de Marquetalia su mito fundacional, con el cual justifican su guerra contra el Estado desde hace cincuenta años. Marquetalia también es visto por el Ejército Nacional como la zona conquistada en la que, de manera obsesiva y a veces desmedida, ha desplegado su fuerza. Pero la vista más apasionada y vigente es quizá la que fijan movimientos religiosos que de distintísimos modos luchan en la fe por un credo que es a la vez telúrico, espiritual y político.

\section{Los guerreros en la fe de Cristo y la conversión del Infierno}

En la actualidad, el cerro Marquetalia es un hato de ganado, con una casa deshabitada y un viento feroz que atraviesa el vacío. Pedazos de aeronaves derribadas y paredes de trincheras derruidas son el colofón de un sitio que ya casi nadie transita y sobre el cual todavía se ciernen las miras. A sus pies se debaten "Las juntas", violentas corrientes de agua que golpean los peñascos y abren continuamente el fondo de los cañones y el tiempo. Entre la selva y los hombres son los ríos los que hacen posible

\footnotetext{
${ }^{30}$ Ibid., pp. 248-249.

${ }^{31}$ URIBE, María Victoria, Salvo el poder todo es ilusión, Bogotá, Editorial Pontificia Universidad Javeriana, 2007, p. 33.
} 
el contacto, ya no solo entre gentes y naturalezas verticales, también entre planos de vida y muerte que ordenan geografías de la lucha por la tierra y el espíritu. Las juntas son el lugar por el que ascendieron muchas veces los colonos y por el que desciende tantas veces la muerte. Cuando un "finado" 32 cae sobre las aguas del río Atá, los campesinos dicen que el río se enfurece, entonces el caudal aumenta. El río siente rabia de cargar con otro muerto y dura un buen tiempo crecido hasta que el mismo río se lleva al difunto y de paso su recuerdo. En las aguas los hombres se bautizan, en el fuego los hombres se consumen, con ambos elementos el hombre se consagra.

Una de las veredas sobre el río Atá, conocida como Altamira, es parte del territorio indígena Nasa. Sus habitantes recuerdan que allí fueron tantos los muertos en la avanzada del Ejército Nacional hacia Marquetalia, que el nombre que tuvo Altamira durante un tiempo fue "El Infierno". Cuando hay bombardeos en la zona -los de antes y los de ahora-, dicen "que la muerte no se deja, que ella sigue trabajando". Los bombazos son tan duros, "que en especial, se sienten en el corazón”. Con las explosiones sienten que todo tiembla durante minutos, "ahí mismo la tierra se prende en fuego como si le echaran gasolina". Sobre esos filos quedaron tantos muertos que una vez, después de un ataque y durante días completos, "los chulos le hacían sombra al sol y los tiempos se hacían oscuros", dice doña Ubaldina Peña. En la imagen colectiva de estos eventos debía ser ese el animal; chulo es el nombre de las aves carroñeras y Chulos son aquellos hombres que transitan junto a la muerte.

Para el pensamiento ancestral Nasa los lugares de fuego, que el cristiano reconoce como "El Infierno", se ubican justo en los nevados. Dentro de los glaciales están las bocas de lava donde habitan la fuerza de la tierra y algunos espíritus. El Nevado del Huila, cima tutelar de esta zona, atrae visiones compuestas sobre el final y cómo ser consumido en el mismo fuego. Doña Ubaldina, indígena Nasa e integrante de la Iglesia Alianza Cristiana y Misionera, dice que este nevado:

Es la cepa, la cabeza de todos los volcanes porque es el más alto. Tal vez por eso todo este territorio será el último en caer cuando llegue el final, cuando se acabe el mundo y ocurra El Juicio Final. Entonces el resto del mundo se acabará primero, de pronto el infierno sea lo último que se acaba. Como el nevado del Huila, es el último infierno por ser el más alto, será el último en acabarse y eso a la gente la protege.

\footnotetext{
${ }^{32}$ Forma en que son llamados los muertos. Proviene de finar, que es consumirse, deshacerse por algo o apetecerlo con ansia [De la versión Online de la RAE 23 Edición]. La muerte vista en clave de apetecer o de ansia, señala un vínculo entre morir, desear y ser consumido. Los finados en cierto modo son objetos de deseo, por eso es que se los bajan, los matan, al tiempo que los consumen. Sin entrar en una compleja discusión a propósito de los vínculos entre antropofagia y muerte, sobra decir que la presencia de la muerte, en estos territorios sacralizados y en pugna, refleja un carácter encantador del muerto que se amarra a la tierra y la contamina, es decir, la prende de su encanto; ese es el carácter especial de un Camposanto o de una zona de guerra. De allí que el territorio donde yace el muerto sea deseado, reclamado, luchado, porque es en la medida en que se está y se tiene ese territorio, que se puede mantener el encantamiento. Si se tiene y se apropia la tierra aquellos muertos pueden seguir encantando (para un tratamiento del "Encantado" en el mundo Andino véase SUÁREZ, 2008).
} 
Purificando la tierra, colonizando el espiritu: conflicto armado y religiosidad...

El credo cristiano se sustenta en reiterar que va a ocurrir un inevitable final. Su concepción teleológica crea una poderosa imaginería que hace del fin de los tiempos una temerosa condensación de salvación, condenación y eternidad. La salvación se contrapone a la condena y para la doctrina, inevitablemente, "El Mundo" se va a condenar en "lenguas de fuego eterno". Los que son como el mundo serán condenados, ellos jamás podrán librarse y estarán en el infierno eternamente. Solo aquellos que siguen a Dios y renuncian al mundo, a la vida finita, serán quienes encuentren la salvación. En la comunidad indígena Nasa Wesx la mayoría de los indígenas creen firmemente en este final sin retorno, razón por la cual conocedores de la palabra de Dios siguen las acciones que los pueden salvar en el seno de la iglesia y la fe de Cristo; siguen la palabra de Dios manifiesta en la Biblia, son guiados por la prédica del Pastor, hacen la liturgia correspondiente y en especial difunden "la palabra" (La Biblia) para que aquellos que no conozcan de Dios también tengan la oportunidad de ser salvados. Con todo, la señora Ubaldina, quien asiste a la Alianza (iglesia evangélica que recoge la mayor feligresía del resguardo indígena), dice que los que viven por los lados del nevado, del Infierno, serán los últimos en acabarse. Por más paradójico que parezca, los indígenas, los creyentes, los campesinos y los guerreros serán los últimos en caer precisamente porque ellos han sorteado El Infierno y aprendieron a vivir en él. Todos ellos ya han transitado por entre las lenguas de fuego, bien sea cubriéndose de las asechanzas del mal, por sentir tan cerca la vitalidad del fuego y sus formas cosmológicas o por haber aprendido a vivir entre la guerra. Dicen los mismos guerrilleros que en la época de la violencia política: “[...] los guerrilleros capturados eran tirados a la boca del volcán Tijeretos"33. Algunos espíritus de la cosmología Nasa habitan dentro de las bocas del volcán, aquellos son los de más fuerza, su temperamento es grave; por ello son temerosos y su contacto puede causar enfermedad o pesar a la gente cuando no se los sabe tratar. Los fieles de la iglesia se enfrentan diariamente a las visiones, tentaciones y pruebas que les pone el Demonio para engañarlos y jalar su alma hacia las brasas de la condena.

LaAlianza Cristiana y Misionera de Colombia es parte de los movimientos protestantes que "hacen énfasis en la conversión como una experiencia esencial para la salvación"34. Su origen es norteamericano y llegó a Colombia en 1923, ingresó por el sur, desde el Ecuador donde años atrás se habían establecido misiones. El primer lugar de trabajo misional en el país fue Ipiales, allí se estableció un Ministerio evangelizador, por medio del cual avanzó la evangelización a otras regiones, haciendo los primeros trabajos de enseñanza del evangelio con comunidades indígenas Guambianas y Paeces en el departamento del Cauca. La Alianza ha tenido un carácter marcadamente rural, aunque hoy día se encuentra una buena cantidad de congregaciones e iglesias en las ciudades capitales. Su estructura teológica se basa en el trabajo de seminarios bíblicos, siguiendo la misión de "hacer discípulos a todas las naciones realizando la labor suprema del trabajo evangelizador"35. Al departamento del Tolima también ingresó

\footnotetext{
${ }^{33}$ ARANGO, Carlos, Op. cit., p. 43.

${ }^{34}$ BELTRÁN, William, Del monopolio católico a la explosión pentecostal. Pluralización religiosa, secularización y cambio social en Colombia, Bogotá, Universidad Nacional de Colombia, 2013, p. 134.

${ }^{35}$ Alianza Cristiana Misionera Neiva, Historia de la Alianza Cristiana, http://www.alianzaneivanorte. org/\#!historia/c1lmq, consultado (28/02/2015) .
} 
por el Sur, a los actuales territorios de Planadas y Rioblanco. Dicen los comuneros que a Nasa Wesx llegó hace unos 60 años y que esta ha marcado de una forma importante la manera en que los indígenas se han relacionado con Dios. Los Nasa se sienten tocados por una influencia misional que ha hecho más presencia y ha ofrecido más bienestar que el Estado o cualquier otra institución en sus comunidades, por lo que dicen, se sienten identificados y también comprometidos con muchas de las cosas que les ha enseñado y brindado la Alianza. Por esto, dicen también, que si la Alianza enseña a hacer unas cosas y dejar de hacer otras debe seguirse esa recomendación, pues admiten que la Alianza promueve lo que puede ofrecer su salvación y evita todo aquello que causa condenación. Si bien esta opinión no es universal, en la comunidad llama la atención que el mismo principio se repite, una y otra vez, casi como una receta por cada uno de los fieles. La doctrina se ha ido afianzando y establece una radical diferencia entre los que conocen el mensaje y lo siguen para ser salvados y aquellos otros que no hacen parte de ese mensaje y esa salvación; son estos los espejos de la condena.

Ser el infierno en la tierra, parece ser lo característico de las zonas de colonización y contacto, también se definen como áreas de guerra y frontera. El conflicto que hizo famoso a Marquetalia, todavía prolonga escenas dantescas de nubes, de aves que devoran las carnes de las víctimas del fuego en los bombardeos. Recordemos que uno de sus puntos de entrada se conoce como El Infierno y que el Nevado solo es la cortina de esas bocas de fuego que salen de las altas y profundas tierras de la Cordillera. En El Infierno no hay ley o Estado y cuando aparecen, lo hacen disparando fuego desde aviones militares o lanzando ataques de plena fuerza. La imagen retoña y se sucede en geografías y escenas, tan distantes pero símiles, como El corazón de las tinieblas de Joseph Conrad, en el Congo Belga; las abominables matanzas de caucheros en la Amazonía peruano-colombiana, en La Vorágine de José Eustasio Rivera; o cientos de escenas locales, nutridas de terror, dolor y fortuna como la zona esmeraldera de Boyacá; las entradas a la Orinoquía, atiborradas de colonos despojados que corren salvando la vida y expandiendo la frontera agrícola; o el mismo departamento del Tolima, que se ha desangrado incesante por sus muertos caídos de todos los bandos. Dirá el coronel Matallana que Marquetalia es una "Selva violenta", por la que lograron fugarse esos bandidos de Tirofijo, de quien dicen en la zona que "es como ver al Diablo en cueros".

Si el Diablo está entre nosotros, entonces algunos actores que lo buscan, que lo asechan e insinúan, también harán parte de esta lógica espiritual y terrígena. Así, el territorio va tomando forma y atributos de acuerdo con los ejercicios de control, ahora quizá más espirituales que políticos. Dicen en la zona que, antes de Estado o insurgencia, fueron los gringos los primeros que llegaron de afuera, religiosos que hicieron su ingreso por el sur desde el Huila y el Cauca. Eran estos, evangelizadores que llevaron la palabra de Dios a las regiones de indios y campesinos. Los mismos pastores dicen que la entrada ha servido porque Dios ha tocado a estas regiones y porque las personas de la zona se han "civilizado" mucho. Con avanzadas de este tipo lograron la autoridad, la legitimidad y el reconocimiento social, otros actores diferentes al Estado. El poder de las iglesias cristianas y también católica generó un orden social que superó otros 
Purificando la tierra, colonizando el espiritu: conflicto armado y religiosidad...

intentos foráneos por regular la vida de las comunidades, muchas veces abandonadas y hasta amenazadas por otra clase de poderes.

Al imperio de la violencia le ha acompañado otro asentado en el credo espiritual, la lucha por el territorio y el control social también se da entre espíritus congregados. ¿De qué modo la vida religiosa ha cobrado tanto significado para las comunidades indígenas y campesinas? A la presencia histórica de estas iglesias puede sumársele a su favor una legitimidad en entredicho de los demás actores. Los habitantes de la zona cuestionan la deuda histórica que las Fuerzas Militares y el Estado han tenido con estas poblaciones, comunidades que no se identifican con los grupos guerrilleros que instigan en el territorio una guerra ajena a ellas, en la cual se han visto forzadas a participar y no de la manera más provechosa. Lo religioso no agota todas las confrontaciones, exigencias y necesidades de una vida en comunidad, antes bien, con la presencia de la iglesia se han agudizado otros conflictos. Aunque estas comunidades indígenas y campesinas se organizan en torno al marco de una guía espiritual y carismática y a la estructura que compone una iglesia para ordenar los preceptos morales, éticos y públicos de su feligresía, tal ordenamiento entra en pugna con otros preceptos religiosos, cosmológicos y espirituales de la tradición de estos pueblos.

Aquellos que no hacen parte de la comunidad de la iglesia -y que como saben decir en la zona, no son "creyentes"- no reciben el mismo tratamiento que los que sí hacen parte de la congregación. Aunque no se trata de una discriminación violenta ni de una segregación que elimina automáticamente al otro en su espacio e individualidad; para "los de La Alianza"36, el que no sigue el Evangelio es una persona que desconoce los caminos de Dios, entonces su paso por la vida es equívoco. No obstante, es el reconocimiento del desconocimiento de Dios en el otro, el que soporta toda la obra de misión, expansión, perseverancia y consolidación del Evangelio. Si hay hombres que no conocen el mensaje de Dios, la palabra y los misioneros que la llevan deben avanzar sin pausa, llevando un mensaje de transformación a toda la humanidad, para llenar los espacios ausentes del credo. Cuando el hombre conoce de Dios y no está con Dios viene la diferencia, el reproche y la condena. Para el "creyente" si se toca a la puerta con el mensaje de Dios y el "no creyente" no escucha, es porque el enemigo no quiere que esa alma se salve y por eso bloquea el entendimiento y no permite que a ese espíritu lo toque la salvación. Allí viene la diferencia redentora; para algunos "creyentes" lo que se debe hacer es persistir hasta que el corazón duro del incrédulo ablande. Por esta razón, en la comunidad de la iglesia se habla de una lucha por la salvación de las almas, una disputa de Dios junto a sus guerreros, que perseveran en la fe y en su mensaje, contra el Demonio y todos los espíritus malignos que quieren arrastrar a la humanidad con ellos a una condenación eterna.

El hombre y su fe son el campo de batalla, allí recaen las advertencias, el dogma, la pasión que se profesa en nombre de la salvación, así como las críticas, las condenas, los odios y las envidias que arremeten en un campo de lucha que traslapa el transcurrir de una confrontación espiritual con una reyerta armada y territorial. El poder de Dios

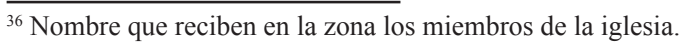


puede ungir a la tierra como a los hombres. Combatientes que en otro tiempo se lanzaron en contra de sus enemigos, patrullando y armando un territorio, ahora se dirigen en una batalla espiritual en la que son "guerreros en Cristo". En el caso de la comunidad Indígena Nasa Wesx, varios de los hombres que hicieron parte de los grupos de Autodefensa que apoyaron al ejército en la toma de Marquetalia, ahora siguen el apostolado de la iglesia y afirman que así como años atrás lucharon con armas de fuego, en la actualidad lo hacen con la espada, la Santa Biblia. Dicen que a esa espada le temen los enemigos más fuertes, que es a la que nadie le puede, porque "la palabra entra mucho más profundo que una bala", como sabe decir Ismael Paya, uno de los pastores evangélicos de la zona.

Un fragmento de la historia de don Justiniano Paya, cacique y capitán de la comunidad Nasa Wesx, es característico de este proceso de transformación del creyente y consolidación de su fe; don Ovidio Paya, autoridad tradicional de la comunidad, cuenta sobre el Capitán y cómo los líderes empezaron a seguir la creencia en los tiempos del conflicto. Don Justiniano era una persona a quien buscaban mucho los religiosos, "se le ponían a la pata" todos los días, al principio le hacían preguntas, lo conversaban. Él decía que era bueno conversar, pero que no lo convencían. Entonces los pastores se dieron cuenta que la palabra podía entrar por donde los golpes de la guerra no le hacían a don Justiniano. Con el tiempo fue cambiando, en una imagen que se guarda con celo en la comunidad aparecía don Justiniano saliendo de la Capilla Cristiana, con una Biblia en su mano derecha y en su costado izquierdo una granada colgando de su cintura. La comunidad, un poco inquieta con el detalle del explosivo y para poder mostrar la imagen, la fue trastocando y en lugar de la granada colocaron una flor.

Ir sobre las almas en blanco, donde el evangelio no ha pasado, es el propósito trascendente de estas doctrinas. Algunos ingredientes del espíritu colono conforman dichas prácticas de la fe. Con la perseverancia en el Evangelio se busca llenar esos espacios sin claras líneas de credo y evangelización e impulsar un espíritu que se afirma por fuera de sí mismo. Su borde se teje hacia fuera, como toda empresa colonial que jamás sacia su espíritu expansivo y que sobre los territorios conquistados compone toda una línea de defensa y filiación, que arrastra hasta los confines.

En una asamblea de iglesias de la Alianza, celebrada en abril de 2013 en la vereda San Pedro, se debatía si los "creyentes" permitían o no que los pastores de la Iglesia Pentecostal hicieran cultos y predicaran en el territorio del Resguardo Indígena. Luego de una discusión en donde se aceptaba que lo que hacía la Iglesia Pentecostal era bueno, porque acercaba los hombres a Dios, se decidió que los pentecostales no podían evangelizar en la zona. Entre las razones que se daban se afirmaba que los de esta iglesia, que era diferente y nueva en la región, acusaban a los creyentes de la Alianza de ser como bestias de tres cabezas por la doctrina trinitaria que lleva la Alianza, a diferencia del modelo unitario de los pentecostales. Otra razón de peso era que una iglesia diferente de la católica y de la Alianza llegaría a dividir a la comunidad y eso no se debía permitir. Los miembros de la asamblea recomendaban a los pastores de la Pentecostal que siguieran su misión en otra parte, que por allí quedaban todavía 
Purificando la tierra, colonizando el espiritu: conflicto armado y religiosidad...

muchos "blancos" en donde se podía difundir el mensaje sin problema. Decía uno de los indígenas que los pentecostales podían ir a las veredas de Alto Sano, a los Guayabos o a Marquetalia, que allá no había ninguna fe predicando.

De acuerdo a la interpretación que ofrece Beltrán ${ }^{37}$ de los movimientos protestantes en el país, la Iglesia Pentecostal Unida de Colombia, que participó en la asamblea de la Alianza, corresponde a lo que él llama el "Pentecostalismo exógeno o pentecostalismo clásico" ${ }^{38}$, que comprende una nacionalización de proyectos misionales extranjeros, más cercanos a la idea de un "protestantismo rutinizado" que reconoce solo la influencia de El Padre en el orden de las cosas del mundo, y mantiene una línea teológica específica que la diferencia de movimientos cristianos de corte carismático que reconocen, además de El Padre, la participación del Espíritu Santo como la fuerza que realiza milagros y también la obra de El Hijo, como ejemplo de misión y apostolado para los fieles ordenando un sistema trinitario de interpretación y fe. En contraste, la Alianza Cristiana y Misionera de Colombia, que para Beltrán corresponde a un "protestantismo Evangélico"39, viene de una tradición norteamericana y conservadora, sin embargo, en la medida que se asienta en un contexto como el colombiano, en zonas rurales o indígenas con grandes carencias económicas y sociales, su doctrina termina aceptando la influencia de lo carismático y va construyendo un modelo trinitario receptivo a los fenómenos milagrosos y a los dones que brinda el Espíritu Santo, entre otra suerte de prácticas más flexibles, incluso cercanas al catolicismo popular. Vale la pena aclarar que existe otro tipo de pentecostalismos más específicos, con una fuerte influencia carismática, que se pueden vincular incluso con prácticas de medicina tradicional indígena o con procesos parecidos a la magia; pero valga decir para el caso, que los pentecostales aquí referidos corresponden, al menos en el plano teológico, a una vertiente más tradicionalista y cercana a la rutina clásica protestante.

Días después de esta asamblea, algunos miembros de la Alianza organizaron una vigilia en la vereda Marquetalia. Invitaron a los hermanos de las demás veredas para que por primera vez se difundiera allí el mensaje de Dios en público. Entrada la noche, luego de alabanzas, prédicas y oración, uno de los líderes más jóvenes pidió por Marquetalia, por esta tierra que había sido manchada por tanta sangre y violencia y que ahora iba a ser limpiada por la Sangre de Cristo. Los pastores pedían para Cristo la vereda de Marquetalia, la reclamaban en su nombre, porque allí se iba a consagrar su honra, honor y gloria. Decían en aquella vigilia que si Marquetalia había sido abundante en violencia, en enfermedad de odio, ahora sería sobreabundante en sanación, en bendiciones y en la presencia de Dios.

La lucha de los cristianos, en su lógica de avanzada, ha dado frutos en la tierra y en los espíritus. La sangre, más cuando es sagrada, limpia las manchas y pecados de las personas, del mismo modo libera de oprobios o sacrilegios a los territorios que han sido objeto de la guerra o alguna impía bestialidad. Con la sangre y el espíritu se

\footnotetext{
${ }^{37}$ BELTRÁN, William, Op. cit., p. 135.

${ }^{38}$ Ibid.

${ }^{39}$ Ibid.
} 
cobra una fuerza que transforma realidades, que "purifica" del pecado, que libera a los hombres y en especial a sus espíritus, que sana la enfermedad y arrastra la locura. Esta lógica de tierras y gentes "recuperadas" es una manera severa de limpiar con aquello que es mácula de una fe o ideario específico. La nueva limpieza de Marquetalia puede responder a una misma lógica de la intervención purificadora, ya no con bombardeos, sino con prédicas, como hicieron con la toma de 1964 y los reiterados ataques de las Fuerzas Militares contra "nefastos bandoleros".

Toda limpieza debe ser total, no puede permitir ambigüedades, por esta razón en dichos territorios “" [...] todos tienen que ir derechitos, y no torcerse para ningún lado, de lo contrario, el fierro los compone" ${ }^{40}$. Aquellos que no están ungidos por la sangre de Cristo no tendrán la vida de quien sí cree en la salvación y está purificado, en todo hombre que tenga mácula o sea de carácter débil el espíritu morirá. Doña Idalba Paya, una mujer que aprecia a aquellos foráneos que vienen a trabajar con las comunidades indígenas, lamenta que las personas que son buenas y hacen el bien a la comunidad, al final serán condenados, pues “[...] no hacen parte del rebaño de Cristo, no están con Él, y da tristeza saber que estas personas y todas las que no hacen parte [de la fe] no van a encontrar la salvación". Al autor de este artículo lo han invitado a acompañar, pero también a conformar la Iglesia de Cristo; los hermanos de la iglesia le han dicho que él es libre de escoger y de hacer algo por el bien de su alma. Pero los mismos también le dicen, que si no busca de Cristo, y no obedece el mensaje será una pena ver cómo se pierde, como aquellos que a Cristo rechazan. Quien no se convierte, en este orden de diferencias, no puede estar en el mismo seno. El libro del Apocalipsis, reiterado en las prédicas sobre el final de los tiempos cuenta:

3:14 Y escribe al ángel de la iglesia en Laodicea: He aquí el Amén, el testigo fiel y verdadero, el principio de la creación de Dios, dice esto: 3:15 Yo conozco tus obras, que ni eres frío ni caliente. ¡Ojalá fueses frío o caliente! 3:16 Pero por cuanto eres tibio, y no frío ni caliente, te vomitaré de mi boca.

\section{Conclusión}

En la entrada de muchos predios de la zona, colocadas en las bases de los cercos que limitan el área de cada propiedad, sembradas en los portales de jardín, se encuentran unas palmas de color rojo escarlata. Algunos no le saben el nombre, otros las llaman Palma de Sangre o Palma de la pasión de Cristo. Las mismas también son utilizadas en los senderos de los caminos al borde del río, pero sobre todo se les ve, como si fueran un bosque, en las tumbas y sitios de entierro de los cementerios de la zona. Los cementerios indígenas no tienen cruces, lápidas o epitafios; solo se sabe que hay una tumba porque están sembradas las palmas encima de cada finado. Sin conocer las características de cada palma es imposible reconocer cuál es el muerto específico. Con los relatos de los moradores, también se identifica que las palmas que contienen muertos son muchas de las que se ven sembradas a la vera del camino. Las tumbas desbordan los cementerios y las palmas sembradas encima de los muertos aparecen en ocasiones junto a los portales de las casas, cuando el muerto sigue morando en el

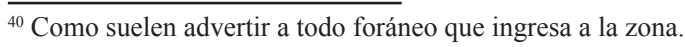


Purificando la tierra, colonizando el espíritu: conflicto armado y religiosidad...

hogar; o sobre los bordes de camino, cuando allí quedaron los muertos producto de las emboscadas y enfrentamientos de los grupos armados.

El territorio se marca -literalmente- con palmas que recuerdan que allí hay mucho muerto enterrado. En indagaciones por el origen de la palma, dice el mayor Gildardo Barón que quienes la trajeron fueron los religiosos, que la plantaron para afirmar la tierra y para que no hubiera más volcanes, más revueltas, por eso es que las tumbas no se ruedan. Don Teodoro Marín, teólogo de la Alianza Cristiana en la ciudad de Armenia, dice que estas palmas “[...] ungen la tierra y evitan que los malos espíritus la impregnen. Esta palma es como el aceite que baña, como la misma sangre de Cristo que limpia y purifica allí donde hay pecado y condena". Recuerda también don Teodoro que la palma puede ser un símbolo, como en aquella narración del libro del Éxodo, cuando sobre Egipto cayeron las plagas y el Ángel avisó que los hijos de Dios debían pintar el portal de sus casas con sangre de cordero, de esa manera cuando llegara el Ángel de la muerte, este no entraría a las casas que habían sido cubiertas por el sacrificio.

La sangre puede limpiar otras sangres, su derramamiento, paradójicamente, puede traer como consecuencia la protección o recuperación de esa sustancia. Una escena reveladora es la del sacrificio ritual, en donde la sangre que es sacralizada purifica al hombre profano. Otra manera de hacerla valer es la consumación de la sangre ajena para purificar o a lo menos recuperar la que es propia. A propósito de la marcha de la vendetta, Páramo menciona que la sangre de la familia, cuando es derramada en la guerra, ha de ser resarcida (reingerida, si se quiere) de idéntica forma a como fue perdida $^{41}$, de tal modo que la sangre caída se recupera cuando la sangre ajena también cae; así, la sangre del otro, cuando se derrama, puede ser tomada y sentida como propia. Estos poderes de una relación agonística hacen posible lo que Hernández Rodríguez llama una "organización a base de la sangre"42, un orden político que reafirma el territorio y la filiación de acuerdo a la sustancia sanguínea, que al ser regada impregna y apropia los espacios, los espíritus, las gentes que se deben a una misma línea sanguínea, ya no contenida sino irrigada.

Para los Nasa, el flujo y la correspondencia de la sangre no pertenecen a una forma individualizada, su sentido es compartido, por lo que la sangre de uno solo es parte indivisible de una sustancia común a todos. La sangre litúrgica, la que los Nasa han regado en sus guerras o la que Cristo derramó por los hombres, es una sustancia de carácter colectivo. En los episodios cosmológicos de origen del pueblo Nasa dicen que la tierra nació de un abrazo de la gente, del que también salieron la sangre y el agua. La unidad en torno a la sangre vuelve a fundamentar el relato de origen. De la voz huracanada de un $N e h w e^{43}$ sale el siguiente reclamo, que vuelve y hace la tierra en sangre:

\footnotetext{
${ }^{41}$ PÁRAMO, Carlos, Op. cit., p. 74.

42 Ibid.

${ }^{43}$ Nombre que reciben los espíritus tutelares, aquellos que crearon a los hombres y permanecen en el cosmos.
} 


\begin{abstract}
$¡ A$ Ah! Ustedes no parecen ser mi gente. Ustedes me dan vergüenza, miren cómo se comportan, miren cómo se pisan los corazones. Ahora, si quieren tener una casa deben abrazarse, deben quererse. Ahora, van a formar una casa grande y yo estaré pendiente de todos porque la casa es una sola para todos. Por más que se oculten en los más recónditos lugares nosotros los estamos mirando. Inmediatamente todos los seres se abrazaron hasta formar una sola masa, como un solo puño y así se formó Kiwe, la "tierra", la casa de todos, Kiwe la mujer. Por efecto de la presión del abrazo, la tierra empezó a brotar agua y sangre. En esa medida la tierra se fue consolidando, el agua y la sangre iban secando y embelleciéndose, se fue cubriendo como de un manto verde, el agua parecía sumergirse en el mismo cuerpo, la tierra cada vez se hacía más joven, cada vez más bella. Conforme se desaparecía el agua se fueron formando los picos de las altas montañas, sus peñazcos [sic], su cuerpo cada vez se maduraba ${ }^{44}$.
\end{abstract}

Los procesos rituales del sacrificio, la purificación o la muerte cumplen un ciclo de retorno a la tierra que sella la posesión sobre la misma. Por ejemplo, la figura del difunto yacente, el muerto sepultado en un territorio que se vuelve propio cuando los muertos de una comunidad o bando se siembran en la tierra en que se vive, da un nuevo sentido a la práctica de tenencia de un territorio, ya que este se torna en un continente de restos y sustancias, en últimas, de formas culturales e históricas que adscriben determinados autores y lógicas a espacios específicos. Los Nasa reclaman la posesión histórica de estos territorios porque allí se encuentran sus difuntos y es ahí donde son posibles las relaciones entre ancestros y descendientes. A su vez, otros actores justifican una clase diferente de presencia, si las FARC reclaman a Marquetalia como el eje fundador de su lucha, es por la propaganda y memoria heroica de sus combatientes, al igual que por los muertos que han ido quedando en este cerro, como en tantos otros epicentros de la guerra. Así mismo, el holocausto de un chivo expiatorio o de una víctima propiciatoria en un sacrificio ritual, refrenda los pactos y las alianzas que hacen posible tanto la posesión espiritual del territorio, como la oportunidad de cooptarlo; al verter la sangre en tierra del sacrificio y esparcir la pureza del sacrificado, tal como lo hacen los fieles de la Alianza con la metáfora de la sangre de Cristo, se legitima y renueva la autoridad de limpiar toda presencia contaminante, eliminando todo aquello que no se identifica con los ejecutantes del sacrificio. Esta misma lógica operaría en términos de los muertos de la guerra, de los asesinatos selectivos con los que un bando busca limpiar la tierra de la presencia de otro, también con los muertos del mismo grupo que son reconocidos como la sangre ofrecida y por lo mismo purificada para el cumplimiento de una causa, en este caso, el control territorial. Un proceso similar ocurre con los rituales de sanación, estos esparcen sobre el territorio el mensaje de una salvación de la tierra y de los hombres, con ello refundan y ofrecen un nuevo significado a las formas de la creencia o el hacer político en contextos del desorden o la anomia social, procurando "sanar" trastornos de las gentes y las regiones, tales como la violencia o el bandolerismo. Este último fue la justificación del Estado para tomarse a sangre y fuego la región de Marquetalia en 1964 y para sostener, como hasta ahora

${ }^{44}$ C.R.I.C, La creación de la casa grande, Sin datos de Edición, 2002, pp. 150-151. 
Purificando la tierra, colonizando el espiritu: conflicto armado y religiosidad...

lo hace, una estrategia militar de alto impacto que elimine la violencia insurgente, haciendo uso de otra clase de violencia, legitimada, justa, normativizada. En todos los casos, el vertimiento y la purificación de la sangre es lo que permite colonizar los espíritus y la tierra. Antes que acciones políticas o económicas, las conquistas de territorios y los creyentes obedecen más a una lógica de orden espiritual y social que crea mecanismos de filiación y permanencia que dan significado y alcance a toda empresa de control social.

\section{Fuentes}

\section{Fuentes Primarias}

\section{Fuentes Testimoniales ${ }^{45}$}

Edilma Paya, habitante de la vereda San Pedro, en Nasa Wesx. Conversación realizada en la vereda Aguablanca, en junio de 2013.

Milciades Garzón, habitante de la vereda Altamira, en Nasa Wesx. Conversación realizada en mayo de 2013.

Ubaldina Peña, habitante de la vereda La Palmera en Nasa Wesx. Conversación realizada en agosto de 2013.

Idalba Paya, habitante de la vereda La Palmera en Nasa Wesx. Conversación realizada en enero de 2013.

Ovidio Paya, exgobernador del Resguardo Paez de Gaitania, habitante de la vereda La Palmera en Nasa Wesx. Conversación realizada en marzo de 2013.

Gildardo Barón, exgobernador del Resguardo Paez de Gaitania, habitante de la vereda San Pedro en Nasa Wesx. Conversación realizada en mayo de 2013.

Teodoro Marín, coordinador del Seminario Bíblico Alianza en Colombia en Armenia. Conversación realizada en marzo de 2014.

\section{Publicaciones seriadas}

El espectador, Bogotá, 1964.

El tiempo, Bogotá, 1964.

\footnotetext{
${ }^{45}$ Los testimonios hechos no corresponden a entrevistas, grupos focales o relatos de vida sistematizados Todos corresponden a la técnica de diálogo informal, concebida como una alternativa de conocimiento en torno a la vida cotidiana en el territorio indígena, en la participación de actos litúrgicos y visitas a las capillas o centros religiosos.
} 


\section{Fuentes secundarias}

\section{Libros}

ALAPE, Arturo, Tirofijo: Los sueños y las montañas 1964-1984, Bogotá, Editorial Planeta, 2007.

ARANGO, Carlos, FARC veinte años. De Marquetalia a la Uribe, Bogotá, Ediciones Aurora, 1984.

ARENAS, Jacobo, Diario de la resistencia de Marquetalia, Medellín, Ediciones Abejón Mono, 1973.

BELTRÁN, William, Del monopolio católico a la explosión pentecostal. Pluralización religiosa, secularización y cambio social en Colombia, Bogotá, Universidad Nacional de Colombia, 2013.

CANETTI, Elias, Masa y poder, Barcelona, Círculo de Lectores, 2005.

C.R.I.C, La creación de la casa grande, Sin datos de Edición, 2002.

FLÓREZ, Diego, Buscando a Gaitania. La crónica de una región que cambió para siempre la historia de Colombia, Ibagué, Caza de Libro Editores, 2011.

HOBSBAWN, Eric, Bandidos, Barcelona, Editorial Crítica, 2000.

INGOLD, Tim, Lines a Brief History, New York, Routlendge, 2007.

MARULANDA, Manuel, Diarios de Campaña, Medellín, Ediciones Abejón Mono, 1974.

MOLANO, Alfredo, Trochas y fusiles, Bogotá, IEPRI \& El Áncora Editores, 1999.

SÁNCHEZ, Gonzalo y MEERTENS, Donny, Bandoleros, gamonales o campesinos: el caso de la violencia en Colombia. Bogotá: Punto de Lectura, 2006.

URIBE, María Victoria, Salvo el poder todo es ilusión, Bogotá, Editorial Pontificia Universidad Javeriana, 2007.

\section{Artículos}

GARCÍA, Álvaro, "Por miedo ayudan a Tirofijo", en El espectador, 27 de Mayo, 1964.

MESA, Elkin, "Eliminación del Bandolero en Potencia”, en El tiempo, 31 de Mayo, 1964. 
Purificando la tierra, colonizando el espiritu: conflicto armado y religiosidad...

PÁRAMO, Carlos, "El corrido del minero: hombres y guacas en el occidente de Boyacá”, en Maguaré, No. 25, Bogotá, Universidad Nacional de Colombia, 2011, pp. 25-109.

SUÁREZ, Luis, "Juan Díaz engañado por la riqueza. Un artífice de la fortuna y la tragedia en el mundo colonial”, en Maguaré, No. 22, Bogotá, Universidad Nacional de Colombia, 2008, pp. 223-289.

\section{Publicaciones en internet}

Alianza Cristiana Misionera Neiva, Historia de la Alianza Cristiana, documento consultado en http://www.alianzaneivanorte.org/\#!historia/c1lmq, consultado $(28 / 02 / 2015)$. 